\begin{tabular}{c} 
International Journal of Engineering \& Technology, $7(4)(2018) 2225-2230$ \\
International Journal of Engineering \& Technology \\
SPC \\
Website: $\begin{array}{c}\text { ww. sciencepubco.com/index.php/IJET } \\
\text { doi: } 10.14419 / \text { ijet.v7it.15788 } \\
\text { Research paper }\end{array}$ \\
\hline
\end{tabular}

\title{
Impact of Climate Change on Water Resources in Huai River Basin, China
}

\author{
Rawshan Othman Ali ${ }^{1,2}$, Arien Heryansyaha ${ }^{3}$, Nadeem Nawaz ${ }^{4}$ \\ ${ }^{1}$ College of Hydraulic and Environmental Engineering, China Three Gorges University, Yichang 443002, China \\ ${ }^{2}$ Petroleum Department, Koya Technical Institute, Erbil Polytechnic University, 44110 Erbil, Kurdistan Government of Iraq ,Iraq \\ ${ }^{3}$ Faculty of Engineering, Universitas IbnKhaldun (UIKA) BogorJalan KH SholehIskandar KM.2, KedungBadak, Tanah Sereal, Kota \\ Bogor, Jawa Barat 16162, Indonesia \\ ${ }^{4}$ Faculty of Water Resources Management, Lasbela University of Agriculture, Water and Marine Sciences, \\ 90150 Uthal, Baluchistan, Pakistan \\ *Corresponding author E-mail: Rawshanothman@yahoo.com
}

\begin{abstract}
Research on the impact of climate change on water resources has attracted the attention of academician and policy makers. This paper tends to analyze the impact of changes in air temperature and rainfall on the amount of water resources in the Huai River Basin from 1980 to 2014. Air temperature and rainfall data were collected from six meteorological stations. Hydrological data were collected from the Bengbu Hydrological Station in the Huai River Basin. Research findings revealed an increasing trend in average annual air temperature, with the highest increase of $0.293^{\circ} \mathrm{C}$ recorded at Bengbu in Anhui Province. The western part of the study area has shown a rising rainfall while the eastern part (the middle reaches of the Huai River Basin) witnessed a declining rainfall. The rainfall in the Huai River Basin was significantly influenced by the natural fluctuations as the average rainfall in the study area was in a vaguely declining trend. This resulted in gradual decrease in the quantity of the Basin's water resources due to decreasing rainfall and rising air temperature. Regression and sensitivity analyses were employed to develop a mathematical model between water resources quantity and changes in air temperature and rainfall. Based on regression analysis findings, changes in rainfall have a much bigger impact on its water resources quantity than changes in its air temperature.
\end{abstract}

Keywords: Climate Change; Rainfall; Air Temperature; Water Resources; Huai River; and Sensitivity and Regression Analysis.

\section{Introduction}

Despite the fact that China is ranked as the world sixth country with highest amount of annual runoff after Brazil, Russia, Canada, United States and Indonesia, it faces many water resources problems and challenges. According to (Global Water Partnership, 2015), annual rainfall decreased in Huai River Basin by $6 \%$ with an evident mismatch (the water resources distribution was $3.4 \%$ from the total annual runoff of 62.2 billion cubic meters According to Huang.et.al, (2006) climate change has the potential to seriously affect China's future national security and sustainable social, economic and ecological development. Climate change poses a serious threat to water resources in China. As a result, the Chinese government announced the China's National Climate Change Program in June 2007 to address climate change issues with specific attention to the country's water. This study tends to address the issue of climatic changes in the Huai River Basin in China. The river is located at a subtropical monsoon zone and can be described as a transitional belt ranging from a humid region to a semi-arid one. Huai River Basin is a major water supply source and the planned passing route for the eastern line of China's South-North Water Transfer Project (See Figure 1). Accordingly, climate change in the region will eventually influence the scheduling and allocation of water in the whole water transfer project. Huai River Basin's rainfall is basically concentrated during the flood season with reasonable variability from year to year. In addition, the river witnesses a frequent presence of natural disasters such as floods and droughts. According to Gao et al. (2008) Huai River Basin results in a impacts seriously on people's life, agricultural and industrial development in the region due to the tem-

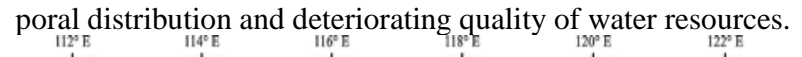

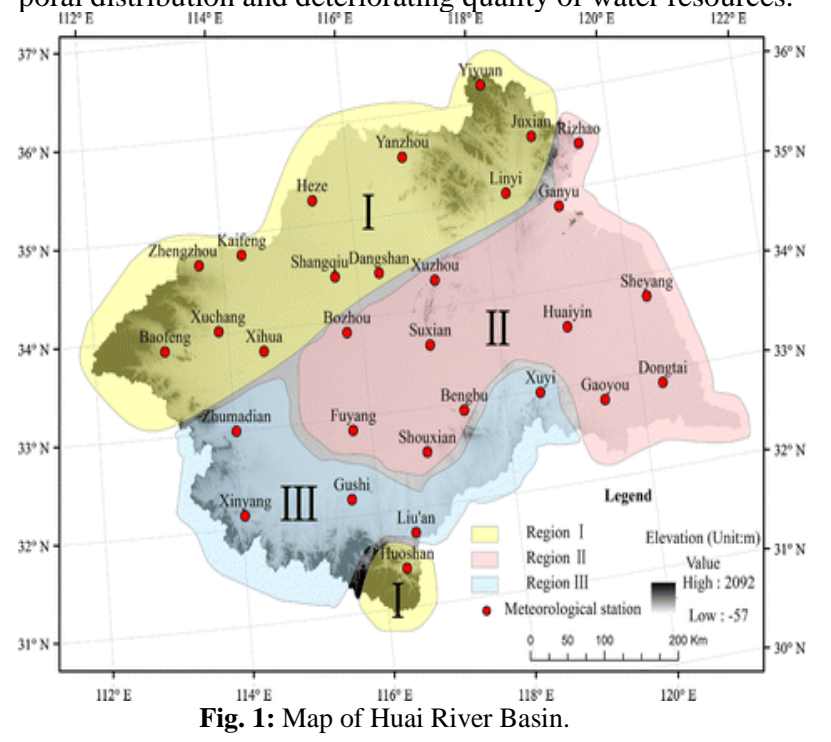


Similarly Che.et.al, (2008), has observed a clear rising in air temperature and apparent falling in rainfall. Prior research on analysis of runoff data for almost 50 years has shed light on falling trends in runoff in Huai River Basin resulting from climate change and coupled with social, economic and other external factors Zhang.et.al, (2001) These have resulted in worsening water supply in the region.. This study seeks to analyze the impact of changes in climatic factors on water resources quantity in the Huai River Basin. To achieve this objective, data collected from six meteorological stations and water resources evaluation data from the Bengbu Hydrological Station from 1980 to 2014 are used to study the pattern of changes in climatic factors and water resources quantity in the river basin. Nathalie, (2007) acknowledged that climate change causes unprecedented challenges to water resources and agricultural systems of northern The increase in temperatures could accelerate worsening water deficits and deteriorating arable lands. In addition, there are higher risks of flooding in coastal cities due to rising sea levels This has a potential of increasing diseases such as malaria. In this regard, Nathalie, (2007) stated that applying the model for the Assessment of Greenhousegas Induced Climate Change (MAGICC) to China scenario revealed that temperatures could well increase by between $0.6^{\circ} \mathrm{C}$ and $1.3^{\circ} \mathrm{C}$ between now and 2030 and from $1.2^{\circ} \mathrm{C}$ to $2.3^{\circ} \mathrm{C}$ by 2050. Recent researches conducted by Gebeyehu.et.al, (2018) have identified the fundamental problems faced in the Huai River Basin: such as effect of climate change, water shortage, flooding, and water pollution. They claimed that the rate and materialization of these problems are higher than other river basins of China because the area is highly productive whereas the available amount of water resources does not meet the demand for various purposes. Building on existing local and foreign research along with the specific situation in Huai River Region, the objective of this study is to employ sensitivity and regression to develop a linear statistical model for testing the relationship between water resources quantity and change in air temperature and rainfall in Huai River Basin.

\section{Research method}

According to Othman.et.al, (2017) causal research design method is most effective in order to establish the cause-and effect associated with specific variations in water resources availability and development The examination of the impact of climate change factors on the processes and relative needs for water uses in domestic, production and eco-water consumption by Researchers is central to the allocation and conservation of water resources in systems of ecology and economy in arid Northeast of China. Othman.et.al. (2017) contended that there are unprecedented increases in the annual temperature trend in Huai River Basin regions.

\subsection{The study settings}

The Huai River Basin $\left(30^{\circ} 55^{\prime} \sim 36^{\circ} 36^{\prime} \mathrm{N}\right.$ and $\left.111^{\circ} 55^{\prime} \sim 121^{\circ} 25^{\prime} \mathrm{E}\right)$ is one of the top seven river basins in China and represents the most densely inhabited River Basin and the main grain-production. It is located in Eastern China between the Yangtze River Basin and the Yellow River Basin. It passes through five provinces: Hubei, Henan, Anhui, Shandong and Jiangsu. The strategic geographical location of Huai River Basin has a distinct position in China's national economy Ning.et.al, (2003) According to Xi.et.al, (2009) Huai River Basin's terrain is high in the northwest but low in the southeast it has various tributaries that join the main trunk of the River and flows into the sea below Hongze Lake. The local climate in the region exhibits strong seasonality. The southern part of the Basin is a subtropical humid zone, while the northern part can be described as a warm-temperate, semi-humid region. The Huai region is affected by different weather systems such as cold vortexes from North China, westerly troughs and, typhoons and easterly waves from the tropics and the Jianghuai Shear Line that result in diversified climate patterns and heavy weather changes. Huai River is one of the main rivers in China with a drainage area covering five provinces: Shandong, Jiangsu, Hubei, Henan, and Anhui Zhang.et.al, (2011). The population of Huai River Basin is ranked as the third highest and it is the main agricultural producing area of China Wang.et.al, (2016). Climate change and human activities such as deforestation, agricultural and urban development, construction of large hydraulic structures and groundwater level drawdown influence the water resources availability in the northern part of China Kløve.et.al, (2014), Yao.et.al,(2015) They stated that the average annual temperature up to 2030 will increase by $0.32^{\circ} \mathrm{C}$ with a more dramatic effect in the northern part of China than southern part Yao.et.al, (2015) Due to climate change, the annual mean runoff of Huai River will decrease by $10.5 \%$ up to 2030 Aiwen, (2001). In the Huai River Basin, water storage index is more than 0.6 and water demand index is above 0.5 , which mean that during drought year there is no water to be stored in the reservoir as the water demand is greater than the annual runoff in a river Aiwen, (2001). According to Peng.et.al, (2018) addressed the significance of global warming and its negative effect on the ecological environment and human society. In their research on the Huai River Basin, They investigated the relationships between temperature indices, as well as those between temperatures indices and the length of the growing season. They stated that the regional responses of extreme temperature indices to global warming across the Huai River Basin were dissected. This study seeks to analyze the impact of changes in climatic factors on water resources quantity in the Huai River Basin. To achieve this objective, data collected from six meteorological stations above the Bengbu Sluice and water resources evaluation data from the Bengbu Hydrological Station from 1980 to 2014 are used to study the pattern of changes in climatic factors and water resources quantity in the river basin. The study at hand focuses on the area between $110^{\circ} \sim 115^{\circ} \mathrm{E}$ and $30^{\circ} \sim 35^{\circ} \mathrm{N}$, located above Bengbu station in Anhui Province. Building on existing local and foreign research along with the specific situation in Huai River Region, bivariate regression was employed to develop a linear statistical model for testing the relationship between water resources quantity and change in air temperature and rainfall.

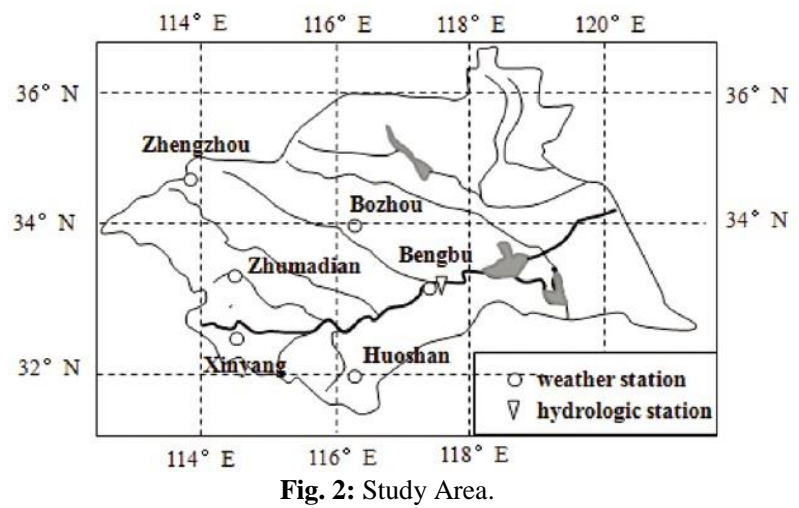

\subsection{Data collection and processing}

The data collection for this study was based on secondary resources. Data on monthly average air temperature and rainfall for six stations in the Huai River Basin located above Bengbu were extracted from "National Meteorological Information Centre" for the 1980-2014 period. These data were provided by China Meteorological Data Sharing Service System (http://cdc.cm.gov.cn/). Similarly, data on water flow, quantity for the three metrological stations above the Bengbu Sluice were properly collected and classified. The meteorological data collected from the China International Ground Exchange Station have been processed and passed strict quality checks. To ensure data continuity, meteorological data from the China International Ground Exchange Station were employed. The data processing has gone through three stages: 
1) Calculating the change trend and trend rate, we let the following time series denote the sequential data of a certain factor:

$X(t)=a_{0}+a_{1} t+a_{2} t^{2} \ldots a_{n} t^{n}$

Where, $\mathrm{X}(\mathrm{t})$ is the factor under study; $\mathrm{T}$ is: time; $\mathrm{a}_{1}$ is linear trend rate; and $\mathrm{a}_{2}, \mathrm{a}_{3} \ldots \mathrm{a}_{\mathrm{n}}$ can be determined by the least squares method. This model can be used to explain the climate change variation in relation to quantity of water resources as argued by Qu.et.al., (2008).
2) Calculating the re-scaled range using the Hurst Index to forecast a future trend. Re-scaled range is a statistical measure of the variability of a time series to provide an assessment of how the apparent variability of a series changes with the length of the time-period being considered. The distribution properties of the Hurst exponents of the temperature and rainfalls data and time series sequences were analyzed using SPSS (IBM, Armonk and NY). After calculating the change trend and trend rate, we use regression/ sensitivity method (R/S) method developed by the British scientist H. E. Hurst for time series research (see Table 1).

Table 1: The Hurst Index Classification List Adapted From (Zhang and Cha, 2008)

\begin{tabular}{llllll}
\hline Level & $\mathrm{H}$ Value Range & Persistence Intensity & Level & $\mathrm{H}$ Value Range & Reverse Persistence Intensity \\
\hline 1 & $0.50<\mathrm{H} \leq 0.55$ & Very weak & -1 & $0.45 \leq \mathrm{H}<0.50$ & Very weak \\
2 & $0.55<\mathrm{H} \leq 0.65$ & Fairly weak & -2 & $0.35 \leq \mathrm{H}<0.45$ & Fairly weak \\
3 & $0.65<\mathrm{H} \leq 0.75$ & Fairly strong & -3 & $0.25 \leq \mathrm{H}<0.35$ & Fairly strong \\
4 & $0.75<\mathrm{H} \leq 0.80$ & Strong & -4 & $0.20 \leq \mathrm{H}<0.25$ & Strong \\
5 & $0.80<\mathrm{H}<1.00$ & Very strong & -5 & $0.00<\mathrm{H}<0.20$ & Very strong \\
\hline
\end{tabular}

Hurst Index method was supplemented and improved by Mandelbrot and Wallis, who developed it into a fractal theory for time series research Mandelbrot and Wallis, (1969).The fundamental principle of this method is divided into four steps. First, we assume $\{\xi(\mathrm{t})\}, \mathrm{t}=1,2,3 \cdots \mathrm{n}$ as the time series. For any positive integer $\tau \geq 1$, we define the mean sequence of the series as:

$<\xi>_{\tau}=\frac{1}{\tau} \sum_{t=1}^{\tau} \xi(\mathrm{t}), \tau=1,2,3, \ldots, \mathrm{n}$

Second, we use $X(t)$ to denote the cumulative deviation:

$$
\mathrm{X}(\mathrm{t}, \tau)=\sum_{t=1}^{\tau}\left[\xi(\mathrm{t})-<\xi>_{\tau}\right], 1 \leq \mathrm{t} \leq \tau
$$

Third, we measure the deviation range, $\mathrm{R}$ which is calculated as follows:

$\mathrm{R}(\tau)=\max _{1 \leq t \geq \tau} X(t, \tau)-\operatorname{Min}_{1 \leq t \geq \tau} X(t, \tau), 1 \leq \mathrm{t} \leq \tau$.

Finally, the standard derivation is defined as:

$$
S(\tau)=\left\{\frac{1}{\tau} \sum_{\mathrm{t}=1}^{\tau}\left[\xi(\mathrm{t})-<\xi>_{\tau}\right]^{2}\right\}^{0.5}, \tau=1,2, \ldots \mathrm{n}
$$

If relationship exist between $\mathrm{R}(\tau) / \mathrm{S}(\tau) \propto \tau^{\mathrm{H}}$ in the analyzed time series $\{\xi(\mathrm{t})\}, \mathrm{t}=1,2,3 \cdots \mathrm{n}$, this indicates the presence of a Hurst phenomenon. The $\mathrm{H}$ value index is defined as the slope of the straight line in the double logarithmic coordinates $(1 \mathrm{n} \tau, \ln (\mathrm{R} / \mathrm{S}))$, obtained from a least squares fit. Hurst Index has different $H$ values $(0<\mathrm{H}<1)$ with different intensities of persistence in the time series as illustrated in Table 1 . For instance, $\mathrm{H}=0.5$ shows a complete independence and random change in the time series. According to Zhang and Cha, (2008) Hurst Index can effectively reveal trendy components in a time series and its value can be used to judge the intensity of persistence or reverse persistence of the trendy components.

3) Regression analysis was employed to establish an annual runoff computation formula for the Bengbu Station to measure the impact of climate change on water resources in the Huai River Basin.

\section{Results}

\subsection{Rainfall change}

Linear regression analysis was conducted to determine the annual rainfall data for the years (1980-2014) at the six stations in Huai River Basin and the values of Trend Rate a1 were obtained. Table 2 showed all the station had an increasing trend of rainfall with the exception of the Zhengzhou Station that showed a falling rainfall trend at a rate of $-1.27 \mathrm{~mm} / 10 \mathrm{a}\left(\mathrm{r}^{2}=0.0004\right)$.

However, declining rainfall magnitude was small and didn't pass significance test .05 . The Bengbu Station had the most notable rising trend, reaching a rate of $28.10 \mathrm{~mm} / 10 \mathrm{a}\left(\mathrm{r}^{2}=0.0419\right)$, followed by Zhumadian, with $14.26 \mathrm{~mm} / 10 \mathrm{a}\left(\mathrm{r}^{2}=0.0059\right)$; Huoshan, with $11.73 \mathrm{~mm} / 10 \mathrm{a}\left(\mathrm{r}^{2}=0.0043\right)$; Bozhou, with $5.21 \mathrm{~mm} / 10 \mathrm{a}\left(\mathrm{r}^{2}=\right.$ $0.0016)$; and Xinyang, with $3.97 \mathrm{~mm} / 10 \mathrm{a}\left(\mathrm{r}^{2}=0.0005\right)$.

Table 2: Annual Rainfall Change Rates and Correlation Coefficients at the Six Stations

\begin{tabular}{llllll}
\hline Station & Zhengzhou & Zhumadian & Xinyang & Bozhou & Bengbu \\
\hline Trend rate a1 (mm/a) & -0.1273 & 1.326 & 0.3972 & 0.5209 & 2.810 \\
Correlation coefficient R & 0.0158 & 0.0736 & 0.0218 & 0.0376 & 0.2051 \\
Hurst index & 0.5192 & 0.6131 & 0.5012 & 0.4735 & 0.5008 \\
\hline
\end{tabular}



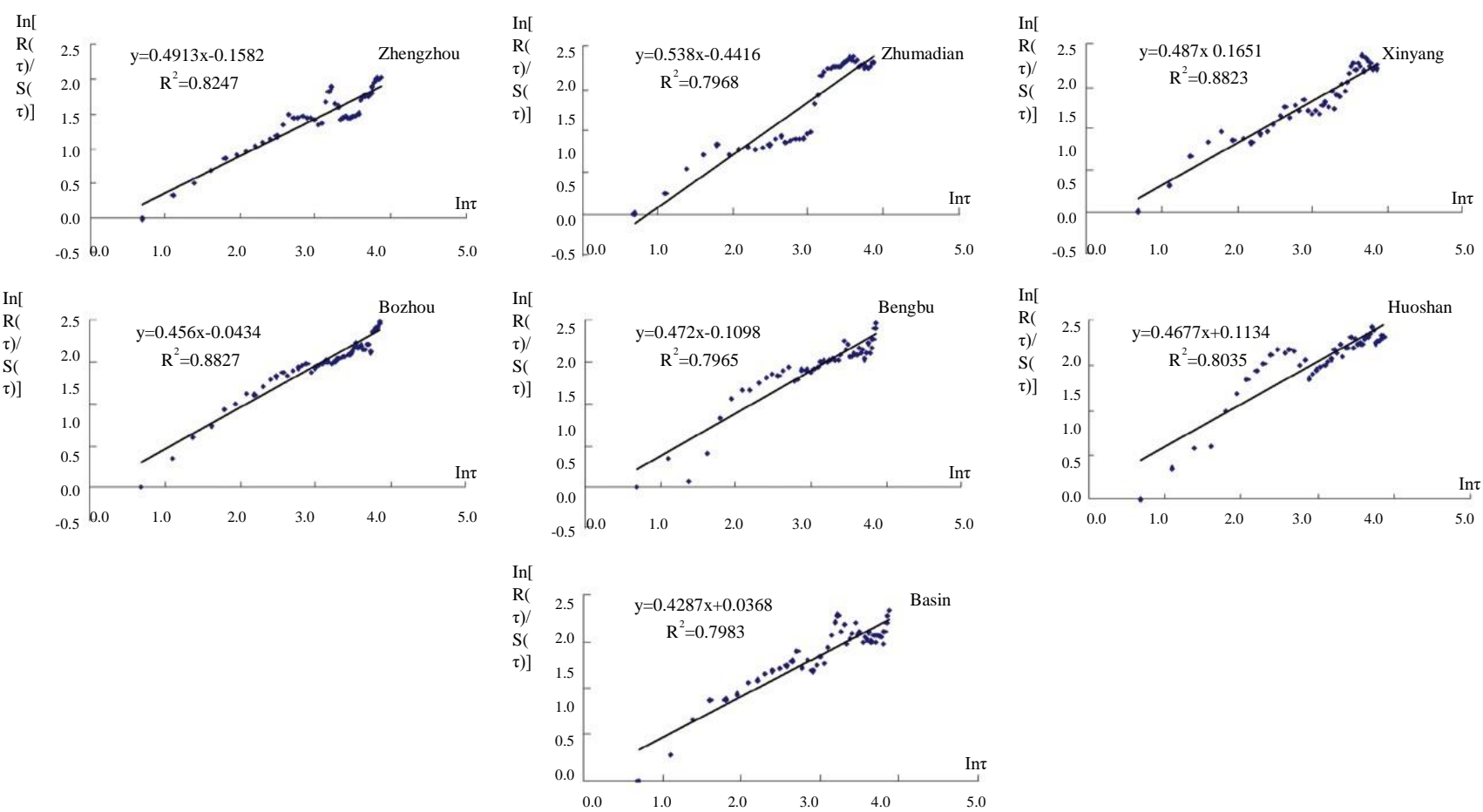

Fig. 3: The Results of R/S Rainfall Analysis in Basin's Six Stations

Concerning the trend rate alone, the rainfall showed a decrease in the northwestern part of the Basin but clear increase in the southwestern part. However, the correlation coefficients were very small in all the cases and failed significance level test. Based on the R/S analysis, Bozhou, Bengbu, Huoshan showed a falling trend. In the study area, average rainfall had an $\mathrm{H}$ value of 0.4287 , indicating a fairly weak persistence (See figure 3). Overall, the falling trend was not noticeable, and rainfall was much affected by natural fluctuations in climate.

\subsection{Temperature change}

All the six stations showed a rising trend of the annual average air temperature especially in Zhengzhou, Bozhou and Bengbu and in the northwestern and southeastern parts of the study area. However, specific changes in average annual air temperature were as follows: Zhengzhou, with $0.258^{\circ} \mathrm{C} / 10 \mathrm{a}\left(\mathrm{R}^{2}=0.339\right)$; Zhumadian, with $0.197^{\circ} \mathrm{C} / 10 \mathrm{a} \quad\left(\mathrm{R}^{2}=0.176\right)$; Xinyang, with $0.189^{\circ} \mathrm{C} / 10 \mathrm{a}$, $\left(\mathrm{R}^{2}=0.247\right)$; Bozhou, with 0.248C/10a $\left(\mathrm{R}^{2}=0.254\right)$; Bengbu, with $0.273^{\circ} \mathrm{C} / 10 \mathrm{a} \quad\left(\mathrm{R}^{2}=0.396\right)$; and, Huoshan, with $0.181^{\circ} \mathrm{C} / 10 \mathrm{a}$ $\left(\mathrm{R}^{2}=0.238\right)$.

Additionally, all the correlation coefficients achieved significance test at the 0.01 confidence level. An $\mathrm{H}$ value of 0.9178 at Huoshan station reveals that the air temperature will continue to rise in the next few years. These findings are compatible with the global warming trend in the Jianghuai region Tian et al, (2005); Lu et al, (2010). Figure 4 illustrates the findings of regression and sensitivity analysis of air temperature analysis.

Table 3: Average Annual Air Temperature Change Rates and Correlation Coefficients at the Six Stations

\begin{tabular}{lllllll}
\hline Station & Zhengzhou & Zhumadian & Xinyang & Bozhou & Bengbu & Huoshan \\
\hline $\begin{array}{l}\text { Trend rate } \\
\text { oC/a) }\end{array}$ & 0.0258 & 0.0197 & 0.0189 & 0.0248 & 0.0273 & 0.0181 \\
$\begin{array}{l}\text { Correlation } \\
\text { coefficient } \mathrm{R}\end{array}$ & 0.5791 & 0.4189 & 0.4874 & 0.5379 & 0.6415 & 0.4964 \\
Hurst index & 0.7804 & 0.8013 & 0.7352 & 0.8105 & 0.8473 & 0.9178 \\
\hline
\end{tabular}



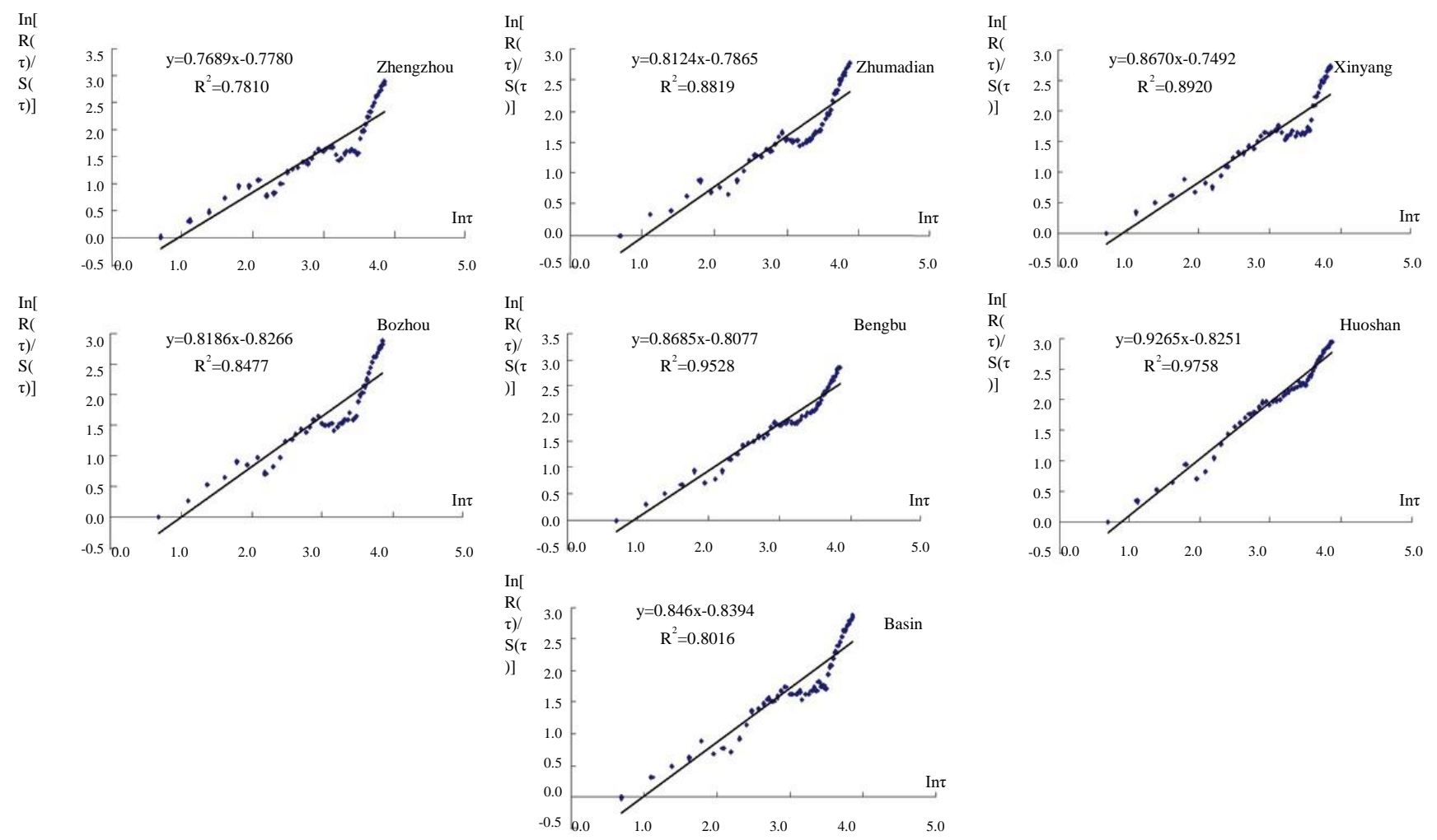

Fig. 4: The Results of R/S Air Temperature Analysis in Basin's Six Stations.

\subsection{Runoff change}

Figure 5 shows the status of change in runoff at the Bengbu Station. The runoff curve didn't reveal a clear trend of change and the linear correlation coefficient involved is very small. It can be observed that there is a gradual declining trend of annual runoff trend with an $\mathrm{H}$ value of 0.4572 , however the intensity of persistence is rather weak.

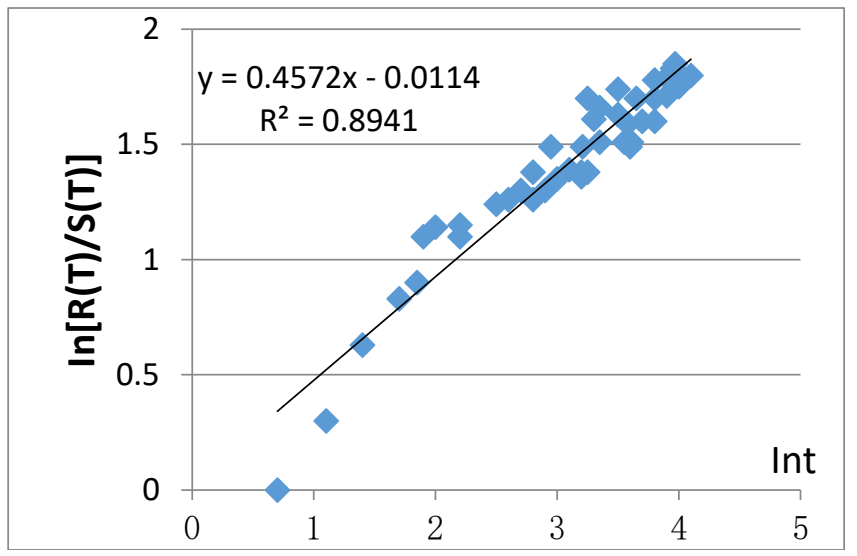

Fig. 5: R/S Analysis Results of Runoff at the Bengbu Station.

\subsection{Regression analysis and statistical model develop- ment}

This study employs a bivariate linear regression to develop a mathematical model between annual runoff (W), average annual air temperature $(\mathrm{T})$ and annual rainfall $(\mathrm{P})$. This model can be applied to quantitatively analyze the impact of climate change on water resources. The general model mathematical equation is:
Where $\mathrm{W}$ is the Annual runoff, $\mathrm{C}$ is Constant, $\mathrm{P}$ is Annual average rainfall and $t$ is average annual air temperature. The least squares method can be applied for bivariate linear regression model to calculate the constant $\mathrm{C}$ and weighted average derived from the station-controlled area/study area ratio. This can be achieved by the following equation:

$X(t)=1 / F \sum_{i=1}^{n}[X i(t) F i]$

Where, $\mathrm{X}$ is the mean of a climatic factor, $\mathrm{t}$ is time; $\mathrm{Xi}$ and Fi: the observed value of the climatic factor at Station $i$ and the area controlled by Station i; and F: the area of the whole study area respectively. This model was applied to the data for the 1980-2014 period in order to identify the natural annual runoff process at the Bengbu Station, its average annual air temperature and rainfall series.

The following results were obtained:

$\mathrm{W}=-44.986+0.748 \mathrm{P}-21.614 \mathrm{~T}$

Where, $\mathrm{R}=0.769, \mathrm{~F}=71.058$, and significance $=0.001$. It can be observed that the correlation coefficient $\mathrm{R}$ is high, $\mathrm{F}$ value is greater than significance, and significance is less than 0.01 . Hence, the significance level test shows a very strong regression findings (see table 4).

Table 4: Annual Runoff Responses to Various Climate Change Scenarios at the Bengbu Station

\begin{tabular}{|c|c|c|c|c|c|}
\hline $\begin{array}{l}\text { Rainfall } \\
\text { Change }\end{array}$ & Air Ter & perature & ige $\left({ }^{\circ} \mathrm{C}\right)$ & & $\begin{array}{l}\text { (Units: \%, } \\
\left.{ }^{\circ} \mathrm{C}\right)\end{array}$ \\
\hline & -1 & -1 & 0 & 1 & 2 \\
\hline-20 & -29.78 & -38.34 & -43.70 & -51.45 & -60.02 \\
\hline-10 & -7.70 & -15.39 & -22.95 & -30.51 & -37.05 \\
\hline 0 & 14.70 & 7.56 & 0.00 & -7.11 & -14.17 \\
\hline 10 & 36.08 & 30.51 & 20.97 & 15.39 & 7.78 \\
\hline 20 & 59.03 & 51.47 & 45.90 & 37.34 & 29.78 \\
\hline
\end{tabular}

Table 4 illustrates the annual runoff in relation to rainfall and air temperature. It is clear that there is an increase in rainfall but de- 
creases in average annual air temperature. Assuming that air temperature is fixed, $20 \%$ of rainfall change leads to -14.7 in runoff change. On the other hand, if we assume that rainfall is fixed, a $10 \%$ increase in rainfall will result in a rise of $20.97 \%$ in average natural runoff at the Bengbu Station, while a $20 \%$ increase in rainfall will increase mean average runoff by $43.70 \%$. On the other hand, if we assume that rainfall is kept unchanged, a rise of $1{ }^{\circ} \mathrm{C}$ in average annual air temperature will lead to a fall of $7.11 \%$ in annual natural runoff, while a $2^{\circ} \mathrm{C}$ increase will cause a runoff decrease by $14.70 \%$ at the Bengbu Station. Overall, Table 4 also shows that the annual runoff at the Bengbu Station is much more sensitive to rainfall changes than to air temperature changes.

\section{Conclusion}

This study has investigated the impact of climate change, more specifically, change in air temperature and rainfall on the quantity of water resources in six metrological stations in the Huai River Basin located above Bengbu Station as well as the change in annual runoff in Bengbu Station. Based on the research findings, the six stations under study area revealed apparent trend of increase in average annual air temperature from 1980 to 2014. In addition, all stations showed a high persistence with a Hurst Index value of over 0.75 . This high value reflects the climate warming in the Huai River Basin and indicates an ongoing rise in air temperature in the near future. The river basin has uneven distribution of rainfall for the 1980- 2014 with a rising rainfall in the western part of the study area and declining rainfall in the eastern part of the Huai River Basin. Furthermore, rainfall in the river is influenced by natural fluctuations as the average rainfall showed an apparent falling trend. On the other hand, the annual runoff for the study period showed an $\mathrm{H}$ value of 0.4743 referring to falling trend despite the weak persistence intensity. The falling trend of runoff occur because runoff is more sensitive to rainfall than to air temperature. Overall, this study has accomplished a mathematical model with different climatic scenarios to test the relationship between change in climatic factors namely rainfall and air temperature, and quantity of water resources.

\section{Acknowledgement}

The authors wish to sincerely thank China Scholarship Council, China Three Gorges University and International Journal of Engineering and Technology. The authors additionally acknowledge the editors and anonymous reviewers of this Journal whose remarks on a prior version incredibly enhanced the quality of the paper.

\section{References}

[1] Huang R H, Cai R S, Chen J L, et al. 2006. Interdecaldal Variations of Drought and Flooding Disasters in China and Their Association with the EastAsian Climate System. Chinese Journal of Atmospheric Sciences, 30(5): 730-743.

[2] GAO G, Chen D L, Xu Y. 2008. Impact of Climate Change on Runoff in the Huaihe River Basin. Journal of Applied Meteorological Science, 19(6): 741-748.

[3] Chen Y, GAO G, Ren G, et al. 2008. Spatial and Temporal Variation of Precipitation over Ten Major Basins in China between 1956 and 2000.Journal of Natural Resources, 20(5): 637-643.

[4] Zhang J Y. 2001. Analyze-evaluation Model of Climate Anomalies Impacts on Water Resources Project Office. Research in Assessment System of Climate Anomalies Impacts on the National Economy. Beijing: Meteorological Press

[5] Nathalie Rousset (2007). The Impact of Climate Change, Wate Security and the Implications for Agriculture. URL: http:// chinaperspectives.revues.org/1213. ISSN: 1996-4617

[6] Gebeyehu AE, Chunju Z, Yihong Z, et al. Overview of prominent problems in huai river basin, China. Int J Hydro. 20182 (1):9-12.

[7] Othman Ali R, Chunju Z, Yihon Z,etal. The effects of human activities, climatic conditions and land-use factors on water resources development in huai river basin northeast china. Int J Hydro. 2018 2 (2):107-114

[8] Ning Y, Qian M, Wang Y T. 2003. Water Manual for Huaihe River. Beijing: Science Press (in Chinese).

[9] Xia J, Cheng X H, Zuo Q T.2009. Comprehensive Carrying Capacity of Water Environment and Control Research in Huaihe River Basin. Beijing: Science Press.

[10] Zhang Y, Arthington AH, Bunn SE, et al. Classification of Flow Regimes for Environmental Flow Assessment in Regulated Rivers: The Huai River, Basin, China. River Research and Applications. 2011 28(7):989-1005. https://doi.org/10.1002/rra.1483

[11] Wang Y, Zhang Q, Singh VP. Spatiotemporal patterns of precipitation regimes in the Huai River basin, China, and possible relations with ENSO events. Natural Hazards. 2016 82(3):2167-2185. https://doi.org/10.1007/s11069-016-2303-3.

[12] Du H, Xia J, Zeng S. Regional frequency analysis of extreme precipitation and its spatio-temporal characteristics in the Huai River Basin. China Nat Hazards.2013; 70(1):195-215. https://doi.org/10.1007/s11069-013-0808-6

[13] Kløve B, Pertti AA, Guillaume B (2014). Climate change affects groundwater and dependent ecosystems. Journal of Hydrology. 2014 518:250-266. https://doi.org/10.1016/j.jhydrol.2013.06.037.

[14] Yao H, Shi C, Shao W, et al. Impacts of Climate Change and Human Activities on Runoff and Sediment Load of the Xiliugou Basin in the Upper Yellow River. Advances in Meteorology. 2015 1-12.

[15] Aiwen Y. Impact of Global Climate Change on China's Water Resources. Environmental Monitoring and Assessment. 2000 61:187-191. https://doi.org/10.1023/A:1006351126446

[16] Peng Sun, Qiang Zhang, Rui Yao, Vijay P Singh and Changqing Song (2018). Spatiotemporal Patterns of Extreme Temperature across the Huai River Basin, China, during 1961-2014, and Regional Responses to Global Changes. Sustainability 2018, 10, 1236 ; https://doi.org/10.3390/su10041236

[17] Feng X L, et al., 2007. Fractal Research of Rainy Day Changing Trend from Tibetan Plateau to Eastern China. Geographical Research, 26(4): 835-843

[18] Qu J N, Ma X Y, ZHANG J X. 2008. Influence of Climate Variation of He-Long Reach to Water Resources. Yellow River, 20(2): $42-44+80$.

[19] Zhang G C, Cha L S. 2008. Analysis on the Future Tendency of Climate Change in Nanjing in the Last 50 Years. Journal of Anhui Normal University (Natural Science), 31(6): 580-584.

[20] Tian H, Li Chun, Zhang S Y. 2005. The Climate Change in the Yangtze-Huaihe River Valley over the Past 50 Years. Journal of Ocean University of Qingdao, 35(4): 539-544.

[21] Lu Y Y, Tian H, Wu B W. 2010. Characteristics of Temporalspatial on Temperature Variation in Huaihe River for Recent 45 Years. Conference proceedings of 27th Chinese Meteorological Society Annual Meeting, Beijing China. 